\title{
Anticorpos contra o vírus da Doença Infecciosa Bursal e detecção do genoma viral em criações de frango de corte e galinhas de quintal no polo avícola da Bahia
}

\author{
Antibodies anti-Infectious Bursal Disease virus and viral genome detection in broilers and chickens \\ backyard at Bahia's poultry production area
}

\author{
Priscila Sousa da Silva ${ }^{I^{*}}$ Tatiane Santana Sales ${ }^{\mathrm{I}}$ Izabella Ramos da Luz $^{\mathrm{II}}$ Paulo César Costa Maia ${ }^{\mathrm{III}}$ \\ Lia Muniz BarrettoFernandes ${ }^{\text {III }}$ Caroline de Oliveira Mendes ${ }^{\text {II }}$
}

\section{RESUMO}

Este estudo teve como objetivo determinar a frequência de anticorpos e detectar o genoma viral do vírus da Doença Infecciosa Bursal em criações de frangos de corte e em criações de subsistência localizadas em duas regiões do polo avícola da Bahia. Foram coletadas 758 amostras de soro de frangos de corte e 320 amostras de galinhas de quintal para avaliação da frequência de anticorpos utilizando ELISA indireto. Para a deteç̧ão e caracterização do vírus foram coletados 6 pools de bursas de Fabrícius em frangos de corte e 3 pools em criações de subsistência, analisados posteriormente com PCR/RFLP. Os resultados revelaram que não há proteção uniforme na criação comercial nas duas regiões estudadas, sugerindo falha na vacinação e desafio com vírus no ambiente. Também observaram-se altos títulos em galinhas de quintal não vacinadas, com variação nos títulos relacionada com desafios de campo. Nos testes moleculares, verificaram-se que três pools de frangos de corte eram positivos, sendo dois para cepa vacinal (G3) e um para cepa variante (G15). Nas criações de subsistência, houve uma amostra positiva para cepa variante (G15). Os resultados demonstram a necessidade de monitoramento em ambas as criações.

Palavras- chave: birnavírus, ELISA, sorologia, biologia molecular, aves.

\section{ABSTRACT}

The aim of this study was to determine the frequency of antibodies anti-Infectious Bursal Disease Virus as well as to detect the virus in broilers and chicken backyard, raised in two different regions at Bahia's poultry production area. A total of 758 serum samples were collected from broilers and 320 from chicken backyard, in order to assess the frequency of antibodies using an indirect ELISA. For virus detection and characterization it was collected 6 bursal pools from broilers and 3 from chicken backyard, which were further analyzed with PCR/RFLP. The results showed that there is no uniform protection in commercial flocks of the two different regions, suggesting that it may be occurring vaccination errors and that it may be occurring challenge from viruses at the environment. High titers were observed in no vaccinated chicken backyard. Molecular tests revealed that 3 broilers pools were positive in which 2 matched the vaccine strain (G3) and 1 a variant strain (G15). One sample from free-ranging chickens was positive for the variant strain (G15). These results demonstrate the need for monitoring both types of exploration.

Key words: Infectious Bursal Disease, ELISA, serology, PCR, molecular biology, chickens.

\section{INTRODUÇÃO}

A Doença Infecciosa Bursal (IBD) é uma doença viral aguda, contagiosa, que afeta aves jovens com 3 a 6 semanas de idade (ASHRAF et al., 2007), causando grandes prejuízos para a indústria avícola (ABDEL-ALIM et al., 2003). O vírus da Doença Infecciosa Bursal (IBDV) multiplica-se nos tecidos linfoides, com predileção pela bursa de Fabrícius, provocando destruição das células linfoides com consequente imunossupressão e aumento da suscetibilidade a outras doenças infecciosas (ELANKUMARAN et al., 2002; BANDA et al., 2003; AL-NATOUR et al., 2004; MORAES et al., 2005).

\footnotetext{
IPrograma de Pós-graduação em Ciência Animal nos Trópicos (PPG), Universidade Federal da Bahia (UFBA), 41720-010, Salvador, BA, Brasil. E-mail: estrelamaior@gmail.com.*Autor para correspondência.

"Laboratório de Sanidade Avícola da Bahia (LASAB), UFBA, Salvador, BA, Brasil

IIIDepartamento de Medicina Veterinária Preventiva, UFBA, Salvador, BA, Brasil.
} 
O IBDV pertence à família Birnaviridae e gênero Avibirnavirus (segundo ICTV 2011) e seu genoma consiste em dois segmentos de RNA de fita dupla (BANDA et al., 2003; ASHRAF et al., 2007). O vírus é constituído de dois sorotipos distintos, denominados sorotipo 1 e sorotipo 2 . O sorotipo 1 é patogênico para aves e sua virulência é variável, e o sorotipo 2 é apatogênico para aves, mas infecta galinhas e perus (BANDA et al., 2003). As mutações genéticas no genoma do IBDV resultaram em variantes antigênicas e patogênicas que continuam a causar a doença em frangos de corte (JACKWOOD \& SOMMER-WAGNER, 2005). A IBD está presente em todas as áreas produtoras de frango e tem causado perdas econômicas para a avicultura industrial em todo o mundo. As perdas estão relacionadas com o aumento da mortalidade e da imunossupressão nas aves acometidas, resultando em queda da performance (KNEIPP, 2000).

A caracterização das cepas de campo do IBDV tem sido fundamental no desenvolvimento de medidas preventivas e campanhas epidemiológicas, tendo como objetivo controlar a propagação do vírus. Nos últimos anos, o uso de técnicas moleculares como a RT-PCR (reação em cadeia da polimerase) tem sido útil na detecção e genotipagem das diferentes cepas de IBDV presentes no campo (NOUEN et al., 2006).

A população constituída de aves que são criadas para o consumo próprio, conhecidas como galinhas de fundo de quintal, não é beneficiada com o programa de biosseguridade, aplicado nas criações comerciais. O conhecimento da ocorrência e distribuição da Doença Infecciosa Bursal em frangos de corte e em galinhas de quintal pode ter grande utilidade para indicar a necessidade de implantação de medidas de prevenção e controle específicas. Uma vez que galinhas de quintal não são vacinadas e são criadas próximas às granjas de frango de corte, este trabalho tem por objetivo determinar a frequência de anticorpos e detectar o vírus em ambas as criações.

\section{MATERIAL E MÉTODOS}

\section{Sorologia}

Foram coletadas 1078 amostras de soro, sendo 758 amostras de frangos de corte e 320 amostras de galinhas de quintal, provenientes de 13 municípios localizados no polo avícola da Bahia, no período de março de 2009 a dezembro de 2010. O número de amostras coletadas em cada município variou de acordo com o tamanho dos lotes de frango e das criações de galinhas.
As amostras foram agrupadas em duas regiões importantes do polo avícola da Bahia, que concentram granjas comerciais de corte e criações de subsistência de galinhas. Em criações de galinhas de quintal, a região de Feira de Santana abrange amostras dos municípios de Conceição da Feira, Feira de Santana e São Gonçalo dos Campos, a região de Alagoinhas abrange amostras de Alagoinhas, Irará e Pedrão. Em criações de frango de corte, na região de Feira de Santana, estão contemplados os municípios de Cruz das Almas, São Gonçalo dos Campos, Sapeaçu, Feira de Santana, Conceição da Feira, Cachoeira e Santo Antônio de Jesus e a região de Alagoinhas abrange os municípios de Alagoinhas, Entre Rios, Coração de Maria e Olindina.

Em frango de corte, as amostras de sangue e a bursa foram coletadas em animais com idade de abate, selecionados aleatoriamente. As aves foram imunizadas com a vacina $\mathrm{Cevac}^{\circledR}$ Transmune IBD aos 18 dias de vida por injeção inovo. Para a coleta de amostras de galinhas de quintal, foram selecionadas aves jovens, previamente anilhadas para possibilitar posterior identificação e coleta das bursas. As aves não eram vacinadas. Tanto nas criações comercais quanto em criações alternativas, as aves não apresentavam sintomatologia clínica da enfermidade.

Os ensaios sorológicos foram realizados no Laboratório de Sanidade Avícola da Bahia (LASAB) UFBA. Os soros foram testados através da técnica de ELISA Indireto utilizando o kit comercial FlockChek* IBD (Laboratório IDEXX ${ }^{\odot}$ ) e os procedimentos do teste foram conduzidos de acordo com instruções do fabricante. Os resultados do teste foram calculados e interpretados utilizando o programa $x C h k^{\circledR}$, em que as densidades óticas (D.O.) de cada uma das amostras são correlacionadas com os controles positivos e negativos da placa em que foram testadas, gerando um índice denominado razão S/P (sample/positive). A razão S/P determina o ponto de corte, ou seja, o valor de densidade ótica no teste que determina os soros positivos e negativos.

As análises estatísticas foram feitas através do programa SPSS 13.0. Os dados foram analisados por meio do teste t de Student, considerando o intervalo de confiança de $95 \%$.

\section{Biologia molecular}

Para detecção do vírus, foram coletadas 09 pools de bursas de Fabrícius, sendo 06 pools de frango de corte e 03 pools de galinhas de quintal. Cada pool continha 10 bursas de aves selecionadas aleatoriamente em frango de corte. As aves criadas no sistema 
alternativo foram anilhadas no momento da coleta de sangue e somente as que tiveram títulos de anticorpos elevados na sorologia foram adquiridas para a realização da técnica de biologia molecular. Todas as bursas foram armazenadas à temperatura de $-20^{\circ} \mathrm{C}$ no LASAB até serem encaminhados para o JF Laboratório, onde foram processadas utilizando a técnica PCR/RFLP. Inicialmente, as bursas foram maceradas em PBS (pH 7,4), com gral e pistilo e estocadas em glicerol. A extração do RNA foi executada com o emprego de fenol-clorofórmio, seguindo a metodologia de SAMBROOK et al. (1989). O RNA foi eluído em $35 \mu 1$. Para a PCR foram utilizados os primers 5'-GGC CCA GAG TCT ACA CCA TAA CTG-3'; 5-CCC GGA TTA TGT CTT TGAAGC C-3' (KIBENGE et al., 1990), específicos para a região variável do VP2, amplificando $248 \mathrm{pb}$ (IKUTA et al., 2001).

A amplificação foi realizada de acordo com MAJÓ et al. (2002), com as seguintes condições: desnaturação a $94^{\circ} \mathrm{C}$ por 3 ', seguida de 40 ciclos de $40^{\prime}$ " a $94^{\circ} \mathrm{C}, 90^{\prime \prime}$ a $55^{\circ} \mathrm{C}$ e $60^{\prime \prime}$ a $72^{\circ} \mathrm{C}$, a extensão final foi realizada a $72^{\circ} \mathrm{C}$ por $5^{\prime}$. Posteriormente, o produto do $\mathrm{PCR}$ foi submetido à eletroforese em gel de agarose a 2\% e corado com brometo de etídio.

Para realização da RFLP, o produto da PCR foi digerido com as enzimas de restrição DraI, SacI, StyI, TaqI, BstNI e SspI (New England Biolabs Inc., Beverly, MA), de acordo com as instruções do fabricante. Os fragmentos digeridos foram submetidos à eletroforese em gel de poliacrilamida a $12,5 \%$ e visualizados após coloração pela silverstaining. Cepas variantes A, Bursine 2, variante E foram usadas como controle na técnica de RFLP (MAJÓ et al., 2002).

\section{RESULTADOS E DISCUSSÃO}

O monitoramento sorológico de plantéis avícolas tem por objetivo analisar os níveis de imunidade materna, determinar imunocompetência, avaliar e reajustar programas de vacinação, diagnosticar surtos de doença e avaliar a biossegurança na granja (TESSARI et al., 2003). O ELISA é o teste sorológico rotineiramente utilizado para detectar anticorpos contra o IBDV, devido ao fato de permitir o processamento de grande número de amostras simultaneamente (ASHRAF et al., 2006).

Os resultados obtidos na análise sorológica das 758 amostras de frango de corte, coletadas de aves em idade de abate estão demonstrados na tabela $1 \mathrm{e}$ nas figuras 1 e 2 . Do total das amostras de frangos de corte analisadas, 90,1\% foram sorologicamente positivas. Nas regiões de Feira de Santana e Alagoinhas, os coeficientes de variação $(\mathrm{CV})$ foram de $54 \%$ e $70,8 \%$, respectivamente.

O coeficiente de variação é uma medida relativa de dispersão bastante utilizada para verificar a uniformidade da resposta humoral e avaliar a eficiência de programas de vacinação na avicultura. RISTOW (2004) classifica os programas de vacinação de acordo com o CV em excelente ( $\mathrm{CV}<30 \%)$, bom (CV entre 30 $50 \%$ ), razoável (CV entre 51-80\%) e ruim ( $\mathrm{CV}>80 \%$ ). Podemos observar que, dentre as amostras de frangos de corte, nos 5 municípios estudados, nenhum teve CV excelente, $20 \%$ bom e $60 \%$ razoável e $20 \%$ ruim. Coeficientes de variação classificados como bons (30$50 \%$ ) demonstram que a imunização do lote foi bem sucedida por gerar títulos uniformes (OPENGART, 2003). Os dados obtidos neste trabalho demonstram que não existe uniformidade nos títulos de anticorpos dos lotes comerciais e, portanto, que o programa de vacinação não conseguiu atingir a proteção esperada nos lotes avaliados.

Verificou-se também grande disparidade na média de títulos nos municípios analisados (Figura 1), com amostras apresentando títulos inferiores a 2500,

Tabela 1 - Distribuição dos títulos de anticorpos, coeficiente de variação, desvio-padrão e frequência de anticorpos em frangos de corte nas duas regiões estudadas.

\begin{tabular}{|c|c|c|c|c|}
\hline & Amostras & Mín-Máx & Desvio-padrão & Coeficiente de Variação (\%) \\
\hline Conceição da Feira & 246 & $1-9.415$ & 2032,1 & 61,7 \\
\hline Feira de Santana & 136 & $1-6.399$ & 1341,6 & 46,7 \\
\hline São Gonçalo dos Campos & 160 & $1-8.498$ & 1577,6 & 83,6 \\
\hline Subtotal & 542 & $1-9.415$ & 1765,7 & 54,0 \\
\hline Alagoinhas & 108 & $\begin{array}{l}\text { egião de Alag } \\
536-12.908\end{array}$ & 2727,5 & 60,7 \\
\hline Entre Rios & 108 & $7-7.092$ & 1886,0 & 71,8 \\
\hline Subtotal & 216 & $7-12.908$ & 2519,5 & 70,8 \\
\hline Total & 758 & $1-12.908$ & 2011,9 & 60,0 \\
\hline
\end{tabular}



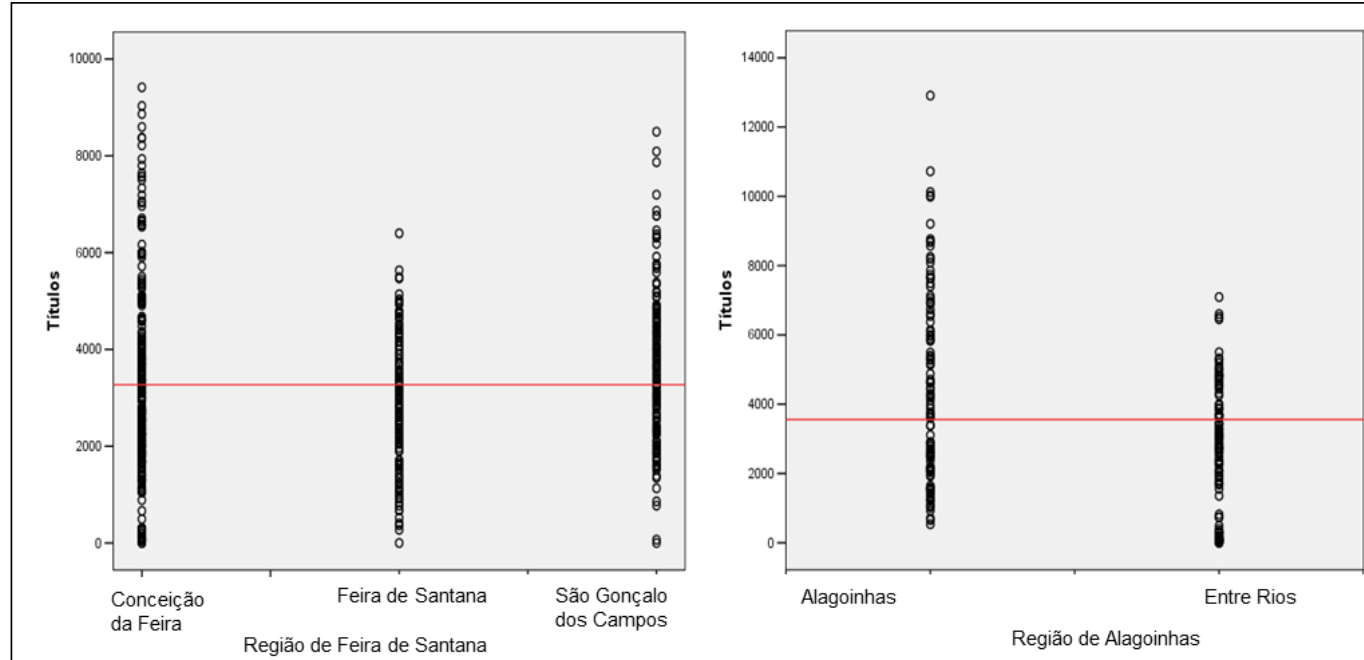

Figura 1 - Distribuição dos títulos de anticorpos contra o vírus da Doença Infecciosa Bursal (IBDV) em frangos de corte da região de Feira de Santana e da região de Alagoinhas com a média de títulos evidenciada.

valor considerado como limite para lotes vacinados, sugerindo que parte das aves não estava protegida, podendo ter ocorrido falha na imunização. Além disso, várias amostras apresentaram títulos superiores a 8.000, sinalizando que deve estar havendo exposição ao vírus no campo (BOLIS et al., 2003). Como todos os lotes foram submetidos ao mesmo programa de vacinação, a coleta foi feita em aves da mesma idade, essa disparidade nos títulos não era esperada, uma vez que a média de títulos de animais vacinados é de 7.000.

Nas criações de subsistência, os dados obtidos também sinalizaram que há necessidade de maior atenção por parte das agências de vigilância epidemiológica, já que a circulação do vírus em criações de fundo de quintal pode proporcionar o surgimento de cepas de maior patogenicidade. Os resultados da análise das amostras de soro de 320 aves criadas em sistema alternativo de criação estão representados na tabela 2 e na figura 2 . As aves não eram vacinadas e não apresentavam sintomatologia clínica. As duas regiões estudadas apresentaram animais com resultados positivos, com índices acima de 50\%. Do total de 320 amostras, 79,7\% foram positivas no ELISA. Observase que nas duas regiões foram obtidos elevados $\mathrm{CV}$,
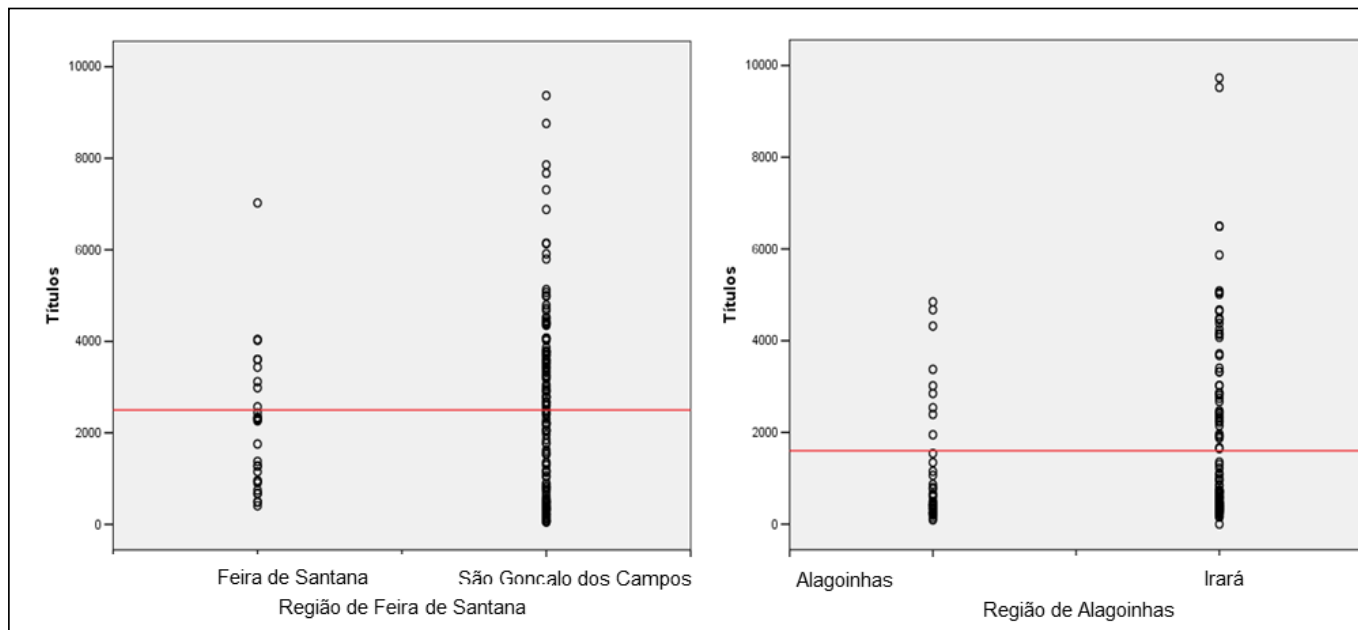

Figura 2 - Distribuição dos títulos de anticorpos contra o vírus da Doença Infecciosa Bursal(IBDV) em galinhas de quintal da região de Feira de Santana e da região de Alagoinhas com a média de títulos evidenciada. 
que sugerem não haver resposta imunológica uniforme nas aves frente a possíveis desafios, uma vez que essas aves não são vacinadas.

Estudo de prevalência de anticorpos contra o IBDV realizado por SANTOS et al. (2008) em galinhas de quintal de 22 municípios no Rio Grande do Sul revelou positividade em $80,2 \%$ das amostras, demonstrando que o vírus está presente neste tipo de criação. Altas taxas de amostras soropositivas também foram encontradas em criações de subsistência avaliadas por VOLK (2005), na Eslovênia e, por HERNANDEZ-DIVERS (2006), no Equador, que obtiveram em seus estudos $78 \%$ e $100 \%$ de positividade, respectivamente. A frequencia alta de amostras positivas contra o IBDV identificadas em criações de galinhas de quintal indica que o vírus circula nessa população (TAN et al., 2004). A circulação do vírus no ambiente em criações alternativas pode ser considerada um risco à indústria avícola, uma vez que os animais que estão localizados próximos às granjas de empresas não apresentam sintomatologia clínica e considerando a capacidade de disseminação do vírus (SANTOS et al., 2008).

A técnica de PCR/RFLP foi utilizada para identificação e genotipagem do IBDV. Os resultados deste trabalho em frango de corte indicaram a presença de padrões de restrição compatíveis com cepas variantes brasileiras do grupo molecular G15 em 01 pool, e de cepas vacinais do grupo molecular G3 em 02 pools de frangos de corte vacinados. Em 03 pools enviados ao laboratório, não houve amplificação específica de ácido nucleico do IBDV da região do gene VP2. Já na análise em criações de subsistência, houve amplificação específica de ácido nucleico do IBDV da região do gene VP2 na amostra da região de Alagoinhas. O grupo molecular G3 é classificado como um grupo de cepas vacinais e o grupo molecular G15 é classificado como grupo de variantes brasileiro com padrões não vacinais e está disseminado em todo o país. Esses resultados demonstram a presença do genoma viral em criações de frangos de corte e em criações de galinhas de quintal, localizadas no polo avícola da Bahia.

Além da proximidade entre as criações comerciais e de subsistência, a presença de vetores e reservatórios do IBDV pode favorecer a disseminação da doença. Estudos anteriores têm sugerido que cães, aves selvagens, roedores e insetos podem ser importantes vetores do IBDV (HOWIE \& THORSEN, 1981; MCALLISTERet al., 1995; OGAWA et al., 1998;PAGÈS-MANTÉ et al., 2004; PARK et al., 2010). A viabilidade do IBDV após passar pelo sistema digestivo de alguns animais foi demonstrada, sendo estes animais considerados portadores e/ou propagadores do IBDV (PAGÈS-MANTÉ et al., 2004; PARK et al., 2010).

Apesar do conhecimento do risco decorrente do surgimento de amostras virulentas e da possibilidade de transmissão para aves silvestres, que podem servir como reservatório do vírus, a relevância da enfermidade em criação de galinhas de quintal não está bem definida (JEON et al., 2008).

\section{CONCLUSÃO}

Neste estudo verificou-se a susceptibilidade das criações comerciais de frangos de corte à IBD, demonstradas nos testes sorológicos e na detecção molecular, bem como foi identificado o risco da presença do IBDV em criações de subsistência. Este é o primeiro relato de detecção genotipagem do IBDV em criações de subsistência na Bahia. Os resultados obtidos reforçam a necessidade de monitoramento constante em ambos os tipos de criação, visando a evitar as perdas relacionadas a essa importante enfermidade.

Tabela 2 - Distribuição dos títulos de anticorpos, coeficiente de variação, desvio-padrão e frequência de anticorpos em galinhas de quintal nas duas regiões estudadas.

\begin{tabular}{|c|c|c|c|c|c|}
\hline & Amostras & Mín-Máx & Desvio-padrão & Coeficiente de Variação (\%) & $\mathrm{N}^{\mathrm{o}}$ aves positivas (\%) \\
\hline Feira de Santana & 30 & $407-7.024$ & 1453,9 & 68,4 & $30(100 \%)$ \\
\hline São Gonçalo dos Campos & 139 & $48-9.370$ & 1973,9 & 76,5 & $117(84,2 \%)$ \\
\hline Subtotal & 169 & $48-9.370$ & 1896,2 & 75,9 & $147(87 \%)$ \\
\hline Alagoinhas & 40 & $93-4.845$ & 1316,9 & 114,2 & $26(65 \%)$ \\
\hline Irará & 111 & $1-9.727$ & 1937,2 & 109,8 & $82(73,9 \%)$ \\
\hline Subtotal & 151 & $1-9.727$ & 1810,0 & 112,9 & $108(71,5 \%)$ \\
\hline Total & 320 & $1-9.727$ & 1906,6 & 91,8 & $255(79,7 \%)$ \\
\hline
\end{tabular}




\section{REFERÊNCIAS}

ABDEL-ALIM, G.A. et al. Characterization of Egyptian field strains of infectious bursal disease virus. Avian Diseases, v.47, p.1452-1457, 2003. Disponível em: <http://www.jstor.org/ stable/i271741>. Acesso em: 15 jun. 2010.

AL-NATOUR, M.Q. et al. Effect of different levels of maternally derived antibodies on protection against infectious bursal disease virus. Avian Diseases, v.48, n.1, p.177-182, 2004. Disponível em: <http://www.bioone.org/doi/abs/10.1637/5319?prevSearch=>. Acesso em: 20 set. 2010 . doi: 10.1637/5319.

ASHRAF, S. et al. Detection of antibodies against serotypes 1 and 2 infectious bursal disease virus commercial ELISA kits. Avian Diseases, v.50, p.104-109, 2006. Disponível em $<$ http://www.bioone.org/doi/abs/10.1637/7436-090805R.1>. Acesso em: 10 jul. 2010. doi: 10.1637/7436-090805R.1.

ASHRAF, S. et al. Development of differential RT-PCR assays and molecular characterization of the complete VP1 gene of five strains of very virulent infectious bursal disease virus. Avian Diseases, v.51, p.935-94, 2007. Disponível em: <http:// www.bioone.org/doi/abs/10.1637/7933-020907REGR1.1?journalCode=avdi $>$. Acesso em: 10 jul. 2010. doi: 10.1637/7933-020907-REGR1.1.

BANDA, A. et al. Molecular characterization of infectious bursal disease virus from commercial poultry in the United States and Latin America. Avian Diseases, v.47, n.1, p.8795, 2003. Disponível em: <http://www.bioone.org/doi/abs/ $10.1637 / 0005-2086 \% 282003 \% 29047 \%$ 5B0087\%3AMCOIBD $\% 5$ D2.0.CO $\% 3$ B2? journalCode $=$ avdi $>$. Acesso em: 12 jun. 2010. doi: 10.1637/00051086(2003)047[0087:MCOIBD]2.0.CO;2.

BOLIS, D.A. et al. Gumboro disease: evaluation of serological and anatomopathological responses in vaccinated broiler chickens challenged with very virulent vírus strain. Revista Brasileira de Ciência Avícola, v.5, n.2, p.137-146, 2003. Disponível em: <http://www.scielo.br/scielo.php?pid=S1516$635 \mathrm{X} 2003000200008 \& \mathrm{script}=\mathrm{sci}$ arttext $>$. Acesso em: 29 jun. 2010. doi: 10.1590/S1516-635X2003000200008.

ELANKUMARAN, S. et al. Pathogenesis and tissue distribution of a variant strain of infectious bursal disease virus in commercial broiler chickens. Avian Diseases, v.46, n.1, p.169-176, 2002. Disponível em: <http://www.bioone.org/doi/abs/10.1637/00052086(2002)046\%5B0169:PATDOA\%5D2.0.CO\%3B2?prevSearch=>. Acesso em: 15 jun. 2010. doi: 10.1637/00052086(2002)946[0169:PATDOA]2.0.CO;2.

HERNANDEZ-DIVERS, S.M. et al. A survey of selected avian pathogens of backyard poultry in northwestern Ecuador. Journal of Avian Medicine and Surgery, v.20, n.3, p.147158, 2006. Disponível em: <http://www.bioone.org/doi/abs/ 10.1647/2005-015R.1?journalCode=avms $>$. Acesso em: 25 jul. 2010. doi: $10.1647 / 2005-015 R .1$.

JACKWOOD, D.J.; SOMMER-WAGNER, S.E. Molecular epidemiology of infectious bursal disease viruses: distribution and genetic analysis of newly emerging viruses in the United States. Avian Diseases, v.49, p.220-226, 2005. Disponível em: <http://www.bioone.org/doi/abs/10.1637/7289-101404R>. Acesso em: 20 jun. 2010. doi: 10.1637/7289-101404R.

JEON, W.J. et al. Very virulent infectious bursal disease virus isolated from wild birds in Korea: Epidemiological implications. Virus Research, v.137, p.153-156, 2008. Disponível em: $<$ www.ncbi.nlm.nih.gov>. Acesso em: 03 mar. 2010. doi: 10.1016/j.virusres.2008.06.013.

KIBENGE, F.S.B. et al. Nucleotide sequence analysis of genome segment A of infectious bursal disease virus. Journal of General Virology, v.71, p.569-577, 1990. Disponível em: $<$ http://vir.sgmjournals.org/content/71/3/569.short>. Acesso em: 25 mar. 2010. doi: 10.1099/0022-1317-71-3-569.

KNEIPP, C.A.F. Doença de Gumboro no Brasil. In: SIMPÓSIO DE SANIDADE AVÍCOLA, 2., 2000, Santa Maria, RS. Anais... Santa Maria: Embrapa, 2000. p.79-88.

MAJÓ, N. et al. Molecular characterization of Spanish infectious bursal disease virus field isolates. Avian Diseases, v.46, p.859-868, 2002. Disponível em: <http://www.jstor.org/ stable/i271736>. Acesso em: 29 mar. 2010.

IKUTA, N. et al. Molecular characterization of brazilian infectious bursal disease viruses. Avian Diseases, v.45, p.297306, 2001. Disponível em: <http://www.jstor.org/pss/1592968>. Acesso em: 19 mar. 2010.

MORAES, H.L.S. et al. Infectious bursal disease: evaluation of pathogenicity of commercial vaccines from Brazil in specific pathogen free chichens. Brazilian Journal of Poultry Science, v.6, n.4, p.243-247, 2005. Disponível em: $<$ http:// w w w. s c i e lo.br/s c i e 1 o.ph p ? p i d = S 1516 $635 \mathrm{X} 2004000400009 \& \mathrm{script}=\mathrm{sci}$ arttext $>$. Acesso em: 23 mar. 2010. doi: $10.1590 / \mathrm{S} 1516-635 \times 2004000400009$.

NOUEN, C.L. et al. Very virulent infectious bursal disease virus: reduced pathogenicity in a rare natural segment-Breassorted isolate. Journal of General Virology, v.87, p.209216, 2006. Disponível em: <http://vir.sgmjournals.org/content/ 87/1/209.short>. Acesso em: 27 jul. 2010. doi: 10.1099/ vir. $0.81184-0$

OPEngART, K. Breeder vaccination programs. Poultry Digest Online, v.3, n.9, p.1-11, 2003.

PAGÈS-MANTÉ, A. et al. Dogs as potential carriers of infectious bursal disease virus. Avian Pathology, v.33, n.2, p.205-209, 2004. Disponível em: <http://www.hipra.com/wps/ wcm/connect/dfa8f2804492e 10 ea 1 c2b1b1192e3c88/ Dogs carriers infectious bursal disease virus.pdf?MOD=AJPERES\& $\mathrm{CACHEID}=\overline{\mathrm{dfa}} 8 \mathrm{f} 280 \overline{4} 492 \mathrm{e} \overline{1} 0 \mathrm{ea} 1 \mathrm{c} \overline{2} \mathrm{~b} 1 \mathrm{~b} 1192 \mathrm{e} 3 \mathrm{c} 88>$. Acesso em: 20 de mar. 2010. doi: 10.1080/030794504200019582.

PARK, M.J. et al. Mice as potential carriers of infectious bursal disease virus in chickens. Veterinary Journal, v.183, p.352354, 2010. Disponível em: <http://www.sciencedirect.com/ science/article/pii/S109002330800422X>. Acesso em: 20 mar. 2010. doi: $10.1016 /$ j.tvj1.2008.12.005

RISTOW, L.E. Considerações para interpretação de resultados sorológicos através da metodologia ELISA em 
avicultura, 2004. Disponível em: <http://www.tecsa.com.br/>. Acesso em: 01 jun. 2010.

SAMBROOK J. et al. Molecular cloning: a laboratory manual. 2.ed. Cold Spring Harbor, New York: Cold Spring Harbor Laboratory, $1989.800 \mathrm{p}$.

SANTOS, H.F. et al. Anticorpos contra vírus em galinhas de terreiro do Estado do Rio Grande do Sul, Brasil. Ciência Rural, v.38, n.7, p.1932-1937, 2008. Disponível em: <http:// www.scielo.br/pdf/cr/v38n7/a20v38n7.pdf>. Acesso em: 27 mar. 2010. doi: 10.1590/S0103-84782008000700020.

TAN, D.Y. et al. Pathogenicity and molecular analysis of an infectious bursal disease virus isolated from Malaysian village chickens. Avian Diseases, v.48, p.410-416, 2004. Disponível em: <http://www.bioone.org/doi/abs/10.1637/7089>. Acesso em: 01 abr. 2010. doi: 10.1637/7089.

TESSARI, E.N.C. et al. Avaliação de kits comerciais de teste ELISA para a detecção de anticorpos contra o vírus da doença de gumboro em plantéis avícolas vacinados. Arquivos do Instituto Biológico, v.70, n.1, p.55-59, 2003. Disponível em: <http://www.biologico.sp.gov.br/docs/arq/V70_1/ tessari.pdf $>$. Acesso em: 3 de mar. 2010.

VOLK, M. Health status of backyard flocks in Slovenia - some preliminary data. Institute for Poultry Health, v.11, p.47, 2005. 